\title{
Knee Disorders Among Carpenters in the St. Louis Area
}

\author{
Lu Yuan*, ${ }^{,}$, Bryan Buchholz ${ }^{2}$ and Ann Marie Dale ${ }^{3}$ \\ ${ }^{I}$ Department of Computer Science and Industrial Technology, Southeastern Louisiana, University, SLU 10847, \\ Hammond, LA 70402, USA \\ ${ }^{2}$ Department of Work Environment, University of Massachusetts Lowell, 1 University, Avenue, Lowell, MA 01854, USA \\ ${ }^{3}$ Washington University School of Medicine, 660 S. Euclid Ave., Campus Box 8005, St. Louis, MO 63110, USA
}

\begin{abstract}
Construction workers, especially carpenters, have a significant number of complaints about knee disorders. Thus, it is desired to identify incident cases of knee disorders and to examine the distribution of specific knee disorders. Clinically sensible algorithms were developed to investigate the medical claims data from the union health plan for carpenters in St. Louis. As a result, 4,900 incident cases of knee disorders were identified among 23,245 medical claims during 1998-2008 and the incidence rate was approximately 153 per 10,000 FTEs (Full-time equivalents). The distribution of knee disorders was $33.1 \%$ for acute, $37.1 \%$ for subacute, and $29.8 \%$ for chronic of the total cases. The majority of carpenters among the total incident cases were Outside Journeymen, who had a much higher percentage of osteoarthritis (32.6\% of their total cases). However, it was also noteworthy that Floor Layer Journeymen were diagnosed with more bursitis (32.1\%) and Outside Apprentices had a higher percentage of ACL (Anterior cruciate ligament) or PCL (Posterior cruciate ligament) sprain $(13.6 \%)$ and fracture $(10.9 \%)$. These results describe the characteristics of knee disorders among union carpenters and provide fundamental health outcome information for further study of knee disorders and occupational risk factors.
\end{abstract}

Keywords: Construction workers, knee disorders, health claims data.

\section{INTRODUCTION}

Knee disorders produce costly disability to construction workers and result in their early departure from work $[1,2]$. Carpenters are one of the most common trades in the construction industry that have experienced this specific misfortune. In particular, floor and carpet layers, some of whom belong to the United Brotherhood of Carpenters and Joiners of America [3], usually spend a great amount of their working time in knee-straining positions, including kneeling, knee-supporting (weight-bearing on the knees), and squatting [2, 4-6]. In addition to prolonged and awkward knee postures, the repetitive operation of the knee-kicker causes a great direct impact to the knee joint $[7,8]$.

Several studies have examined the association between kneeling and knee osteoarthritis (OA) among construction workers. Vingård et al. [9] found greater risk among male construction workers than other occupational groups. Carpet and floor layers had increased risk of patellar osteophytes, but not tibiofemoral joint degeneration, compared with a reference group of house painters [10]. In a separate investigation conducted by Kirkeskov Jensen et al. [11], both carpenters and floor layers, especially those over 50 years of age, had higher prevalence of radiologic OA compared with compositors (seated layout work on video display units). Kirkeskov Jensen et al. [12] suggested a dose-response

*Address correspondence to this author at the Department of Computer Science and Industrial Technology, Southeastern Louisiana, University, SLU 10847, Hammond, LA 70402, USA; Tel: 1-985-549-3925; Fax: 1-985549-5532; E-mail: Lu.Yuan@ @elu.edu correlation between knee-straining work activities and the development of self-reported knee complaints and radiologically diagnosed knee OA. A recent case-control study in Germany also supported a dose-response relationship between kneeling/squatting and symptomatic knee OA, where carpenters had an elevated knee OA risk for a cumulative exposure to kneeling and squatting over 10,800 hours [13].

A broader set of knee problems, such as bursitis, was also in excess among floor and carpet layers [14]. The clinical findings reported by Rytter et al. [15] suggested that possible meniscal lesions were significantly more prevalent among floor layers compared to a group of low-level exposed graphic designers.

Other studies focused on the examination of generic knee symptoms for carpenters. Among 5,000 German construction workers, the prevalence of musculoskeletal disorder (MSD) examination findings in the arms and legs was highest in carpenters compared with six other trades [16]. Dimov et al. [17] found that $45 \%$ of carpenters had knee discomfort and Lemasters et al. [18] reported increased risk of knee symptoms among carpenters with at least 20 years of employment history, as well as those with daily fatigue and little influence over the work schedule.

It should be recognized that while the majority of previous studies focused on the examination of floor and carpet layers, the predominant data sources came from either selfreported questionnaires or radiological investigations or both. Research that uses medical insurance records may study the characteristics and risks of knee disorders among a broader range of carpentry specialties in a large population. 
Since the early 1970 s, administrative databases have provided invaluable information about questions of cost, quality, and outcomes of treatment for epidemiologic, health research, and clinical studies [19-22]. Using combined data sources, including union administrative records and workers' compensation claims, Lipscomb et al. [23] estimated the rate of work-related knee sprain-strain in Washington State unionized carpenters to be 1.1 per 200,000 work-hours (100 FTE workers per year), of whom only $47 \%$ had compensated lost work time for the condition.

On the other hand, the disadvantage of administrative data is the lack of specific clinical details, and the potential for misclassification of diagnoses or procedures. For example, the coding may reflect individual, local or regional biases, as well as the possible inaccuracies in physician diagnosis. Diagnoses assigned to claims may be presumptive and later ruled out. However, other authors have found that these problems did not unduly compromise their ability to investigate a variety of different epidemiologic hypotheses in medical claims data [24-26]. In an autoworker study conducted by Punnett [27], the author applied a feasible algorithm to distinguish incident from recurrent health events. In consultation with the corporate occupational health nursing and medical staff, it was determined that the database administrators applied a rule that a condition was defined as "recurrent" if medical care was sought within two months of a previous visit for a disorder affecting the same body area. While this was an unavoidably arbitrary criterion, it nonetheless helped identify administratively unique cases and computer MSD rates.

Therefore, it is imperative to accurately code specific knee diagnoses so that the knee disorder characteristics can be better understood. The main objective of this study was to use an administrative database to identify and group knee disorders, evaluate the case definitions, determine incident disorders, and describe the occurrence of these disorders in a working population of union carpenters in the St. Louis area.

\section{MATERIALS AND METHODOLODY}

\section{Data Sources}

The Carpenters' Health and Welfare Trust Fund of St. Louis includes a total membership of approximately 30,000, of which about 15,000 members are currently active including 5,000 members added since mid-2003 from southern Illinois. Eligibility for benefits is based on the number of hours worked in a given calendar period. Members gain initial eligibility by accruing work hours during apprenticeship training or any subsequent time. Initial eligibility requires working 500 hours in a consecutive 6-month period. Eligibil- ity is retained by members working a minimum of 250 hours in a 3-month contribution quarter or 1000 hours during the previous 12 months. There are 4 contribution quarters during the year providing member benefits during benefit quarters. Table 1 shows the eligibility schedule.

Members who do not work the required minimum number of hours may use various self-pay options to maintain coverage. Members who do not continue coverage under the plan through self-payment and lose eligibility for longer than one year, are required to meet the initial eligibility requirements of 500 hours to become eligible again.

Hours worked by members are recorded by contractors through an internet-based reporting process. Contractors are required to submit work hours electronically to the Fund. This procedure was made mandatory in January, 2002. All benefits through the Fund are linked to the number of work hours recorded in this system.

Members of the union are employed by commercial, residential and floor laying contractors. The majority of the members work as Outside Carpenters, who specialize in a variety of sub-trades including piledriving, millwright, commercial frame hanging, lather, commercial ceiling tile installing, commercial access floor laying, commercial removable partition, residential framing, residential drywall hanging, and residential trim finishing. Other typical specialties include floor layers/installers, inside carpenters, and roofers, etc. Floor layers are further divided into subspecialty groups in hardwoods, carpet, vinyl composite, and ceramic tile; whereas inside carpenters work in shops and mills, specializing in millwork, display, and cabinet, respectively. Outside carpenters and floor layers have separate local unions but the carpenters' union administers the floor layers' personal health claims and provides the benefits for the floor layers. This was changed around 2003 but the claims filed by floor layers prior to 2003 were added to the full database.

Records of all medical insurance utilization by members of the Fund are available in seven record types. These records provide the following information on each medical visit: CarpenterKey (individual identification number), gender, date of birth, job class (general class of job titles that differentiates among trainee, apprentice, journeyman, disability, and retiree, etc.), period of year (year that a carpenter is eligible for benefits), eligible months (total months that a carpenter is eligible for benefits within a given year), work type (contractor coded category of work, initiated in 2000), dates of record (including BeginDate and EndDate of a specific claim), ICD-9 (International Statistical Classification of Diseases and Related Health Problems) codes, and CPT

Table 1. Eligibility Schedule for the Carpenters' Health and Welfare Trust Fund of St. Louis

\begin{tabular}{|c|c|c|}
\hline Contribution Quarter (hours worked) & Benefit Quarter (Charges incurred) \\
\hline \hline August, September and October & For coverage in & January, February and March \\
\hline November, December and January & For coverage in & April, May and June \\
\hline February, March and April & For coverage in & July, August and September \\
\hline May, June and July & For coverage in & October, November and December \\
\hline
\end{tabular}




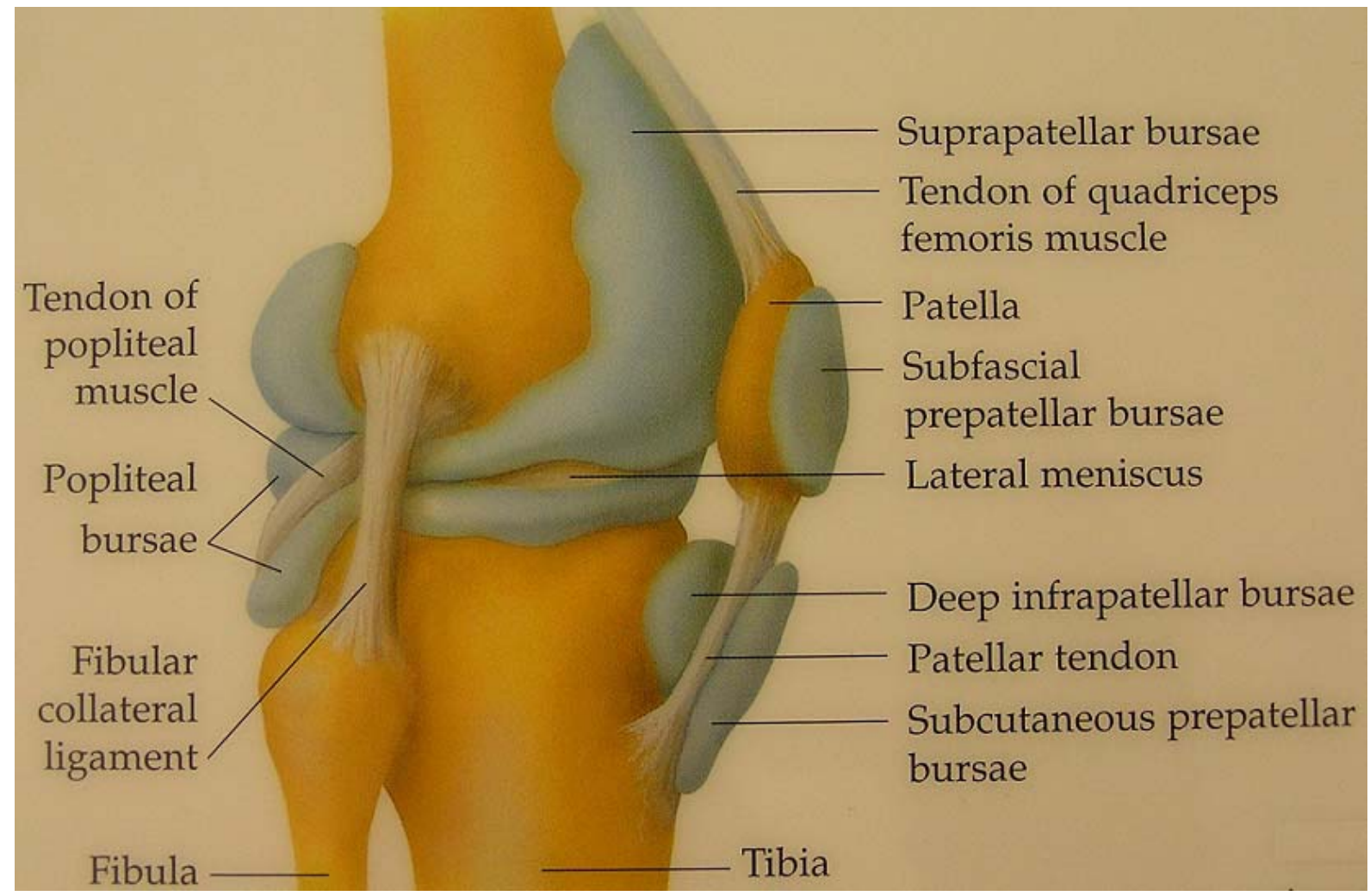

Fig. (1). Structure of the Knee (Courtesy of Anatomical Chart Company, Skokie, Illinois).

(Common Procedural Terminology) codes. The CPT codes comprise a standard and frequently utilized procedural coding system that captures surgical procedures, therapeutic injections, and types of visits (such as initial, follow-up, and level of intensity of care provided).

\section{Coding of Incident Cases}

The knee may be the anatomic target of a wide range of disabling, painful disorders (Fig. 1).

One of the important challenges is to group these disorders into broad categories that are large enough to provide sufficient cases for analyses, yet conceptually distinctive for analytic purposes. Another challenge in using claims data is to distinguish prolonged (chronic) episodes of a disorder from recurrent episodes. For example, if a patient with a patellar syndrome is seen three times in a year, each visit four months apart, does this represent three separate episodes with symptom-free intervals between episodes, one continuous episode lasting a year, an initial episode and subsequent longer episodes, or yet another temporal sequence? In fact, it is hard to distinguish these possibilities cleanly but clinically sensible algorithms can be used, similarly as previous studies [25-27], to develop a crude classification system to group disorders as acute, subacute or chronic. Table 2 shows the specific disorders in each of these broad categories, along with the particular diagnostic entities in each category.

In order to develop functional definitions of presumed incident and recurrent episodes, it was planned to further develop separate algorithms for acute, subacute, and chronic conditions and then assess them in light of the available treatment data. The definition for each chronicity category is as follows:
For the acute category of knee injuries, it was assumed that the first mention of a diagnostic code within a series of visits represents a new episode. The series of visits is considered to end when there has been a two-month period with no additional treatment to the same knee. A recurrent episode occurs if a subsequent episode has the same diagnosis in the same knee.

For the subacute category of disorders, a single episode was defined as lasting less than six months. Thus, if two visits occur within six months of one another they will be defined as the same episode. If a six-month period separates visits, the visits correspond to separate episodes. According to this assumption, the example above of three visits, each four months apart, would be classified as a single prolonged episode.

For the chronic category, which is defined to include only OA, the date of onset is difficult to determine. While there may be recurrent episodes of pain or inflammation, these are unlikely to represent new occurrences. Hence the date of onset for an OA case is defined as the date that OA is first mentioned in the administrative database without considering the subsequent episodes.

The classification is clinically intuitive, operationally simple, and permits clinically credible hypothesis testing. However, several limitations should also be recognized. First, workers may (and often do) have more than one diagnosis. For example, it is common to have a pre-existing symptomatic OA and a variety of superimposed lesions including pes anserine bursitis and meniscal pathology. Second, some entities could reasonably be placed into more than one category. For example, meniscal injuries, as categorized 
Table 2. ICD-9 Codes for Clinical Entities and Percentages of Knee Disorders

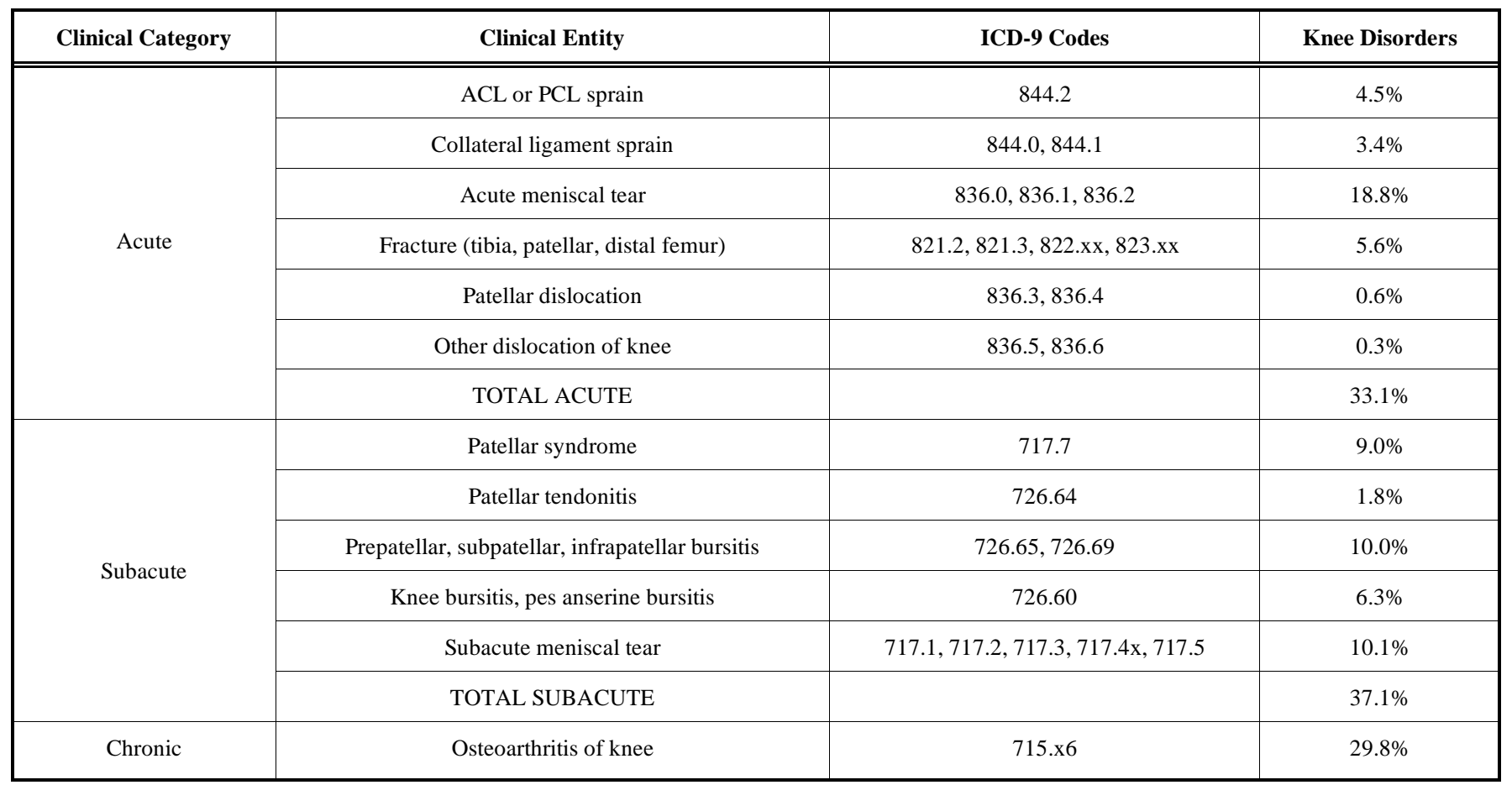

here, can be either acute (following an injury) or subacute (with no clear date of onset and no imminent resolution). Therefore, the following list of rules was developed in order to more accurately identify the incident cases:

1. CarpenterKey is the first variable to examine. If a carpenter had only one claim and the claim had one diagnostic code, it was counted as one incident case. If a claim had multiple diagnostic codes, multiple incident cases were recorded in the order of chronic, subacute, and then acute clinical categories.

2. If a single carpenter had multiple claims and each claim had one diagnostic code, the beginning and end dates of the claims would be reviewed along with the diagnostic codes. If the claims occurred in the order of acute, subacute, and/or chronic within a six-month period, these claims were only counted as one incident case with the assignment of the most chronic clinical category. If the order of the clinical category was the opposite (chronic, subacute, acute), those claims were counted as multiple cases.

3. Clinical Entity in Table 2 was used to represent the health outcome variables. This categorized several ICD-9 codes into one clinical entity. So the claims with different diagnostic codes (but representing the same clinical entity) were considered as one single case, after the above assumptions were applied.

\section{Data Analysis}

Cases of knee disorders were identified using ICD-9 diagnoses provided in health care utilization records for the past 11 years (1998-2008). Using an estimate of total eligible members in the database, the incident rate of knee disorders was computed. Due to the fact that the available total hours of work in the current study were recorded only on the car- penters who had filed claims from 1991 to 2006 and the incident cases were coded from 1998 to 2008, we estimated the incident rate based on a yearly average of FTE (Full-time equivalent) rather than an actual rate.

The distribution of specific disorders in the cohort by demographic characteristics (such as gender and age groups) and job class was examined. In particular, the proportion of typical knee disorders including OA, meniscal tear, bursitis, ACL/PCL sprain, and fracture when stratified by job class were compared to investigate the effects from work factors.

\section{RESULTS}

\section{Descriptive Statistics}

A total of 4,900 cases of knee disorders were identified among 23,245 eligible medical claims. There was an estimate of 29,022 eligible members in the database, so the incidence rate of knee disorders among carpenters in the St. Louis area during the 11-year period was approximately 153 per 10,000 FTEs.

As shown in Table 2, the three categories of acute, subacute, and chronic knee disorders made up $33.1 \%, 37.1 \%$, and $29.8 \%$ of the total incident cases, respectively. The most frequently occurring single type of knee disorder was OA $(29.8 \%)$, followed by acute meniscal tear $(18.8 \%)$ and subacute meniscal tear $(10.1 \%)$ which indicated a combined total of $28.9 \%$ for meniscal tear. The combined percentage for bursitis (prepatellar, subpatellar, infrapatellar bursitis, knee bursitis, and pes anserine bursitis) was $16.3 \%$.

\section{Distribution of Specific Disorders}

Nearly $98.2 \%$ (4814 of 4900) of the incident cases were for male carpenters. Female (60 of 4900) workers had a slightly higher percentage of OAs $(31.7 \%)$ than males 


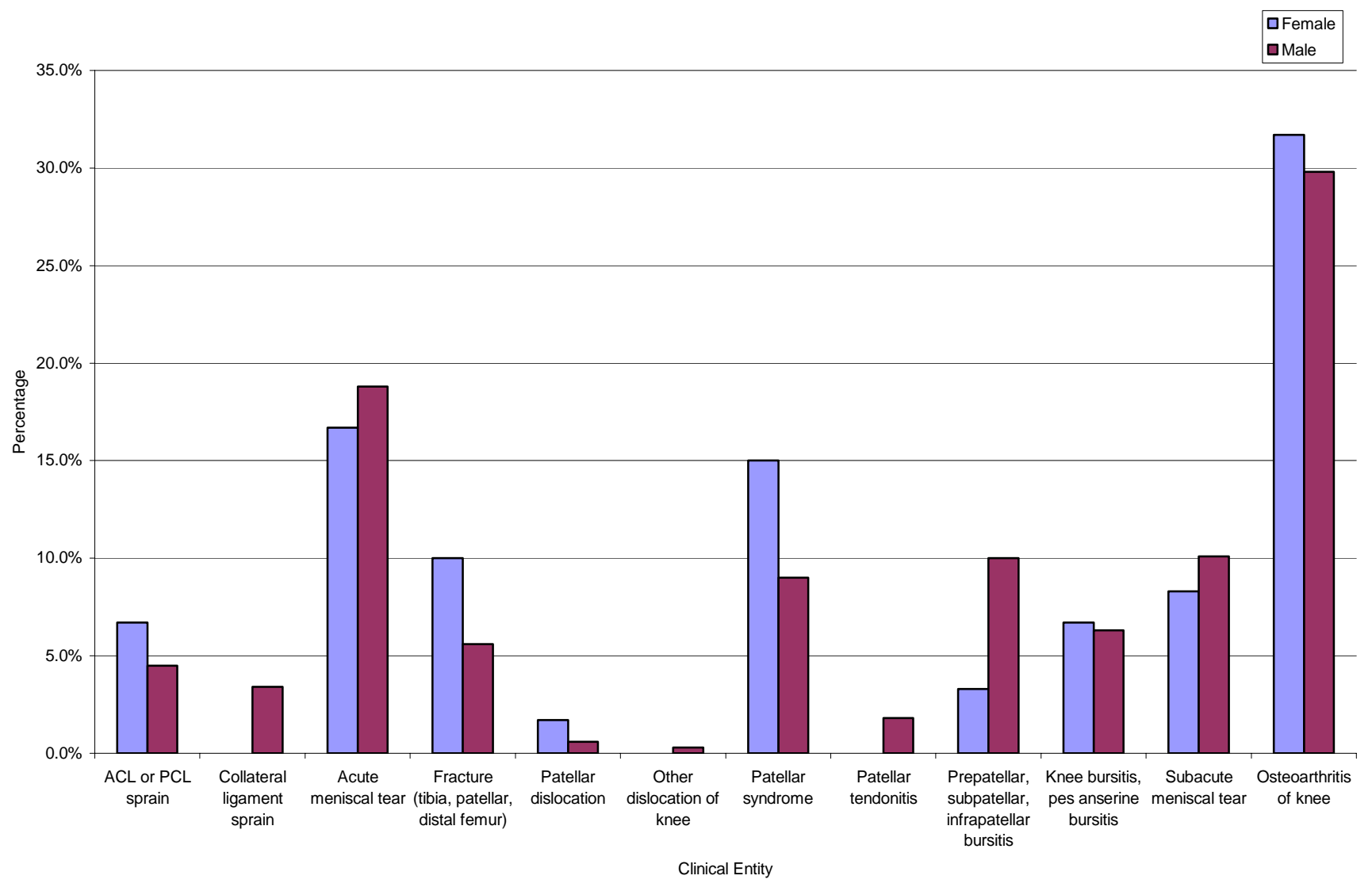

Fig. (2). Distribution of knee disorders stratified by gender.

$(29.8 \%)$. On the other hand, males were diagnosed with more bursitis (16.2\%) than females (10.0\%) (Fig. 2).

Within the three age groups $[<30$ (665 of 4900), 30-44 (1448 of 4900), 45 and older (2787 of 4900)] that were assigned based on the date of onset, a clearly increasing trend (Fig. 3) was seen for the proportion of OA cases in the oldest worker group. However, older workers had a lower proportion of acute and subacute knee cases compared to younger workers, especially ACL or PCL sprain, fracture, and bursitis.

When these knee disorders were linked to the types of job class (Table 3), it was found that Outside Journeymen (3800 of 4900) had a much higher percentage of OA (32.6\%), whereas Floor Layer Journeymen (308 of 4900) were diagnosed with more bursitis $(32.1 \%)$ and Outside Apprentices (257 of 4900) had higher percentages of ACL or PCL sprain (13.6\%) and fracture (10.9\%).

\section{DISCUSSION}

The present study used an administrative database to identify incident cases of knee disorders and to examine the distribution of specific disorders stratified by different demographic and available work factors. The estimated incidence rate of knee disorders was 153 per 10,000 FTEs. Female workers had a slightly higher percentage of OA but lower bursitis compared to male. Older workers were diagnosed with more OA, whereas younger workers had more acute injuries. Floor layers exposed to long periods of kneeling had higher bursitis.
The population burden of knee disorders has not been well described except in the case of OA. Picavet and Hazes [28] reported that $15 \%$ of the general Dutch adult population had OAs. Based on radiographic evidence that is commonly used to define cases for epidemiologic studies, Spector and Hart [29] estimated that 14-30\% of people over the age of 45 in the United Kingdom have knee OAs. In the present study, the percentages of OA cases among all the incident cases indicated a much higher rate of $\mathrm{OA}$ for the union carpenters. Although this study used a personal health claim system which may include both occupational and non-occupational injuries and disorders, we surmise that the higher rate of OA in this study is due at least in part to the occupational exposures.

The incident rate in this study is approximately half of the incident rate that was computed in a separate study of carpenters from the Carpenters' Combined Benefits Fund of Massachusetts (286 per 10,000 person-years) [30]. It should be noted that the work in Massachusetts is dominated by heavy commercial construction, both buildings and highway, whereas the work in St. Louis has a much higher proportion of residential construction. Also, the estimate of total eligible carpenters in Massachusetts' database is much cruder.

Both rates we calculated tended to be higher than what have been reported in other studies [18, 23]. Because the Fund used in this study is a personal health fund, it does not normally cover work-related injuries/illnesses. Nonetheless, if the claims are not captured by workers' compensation because of its chronic pattern of development, they will be 


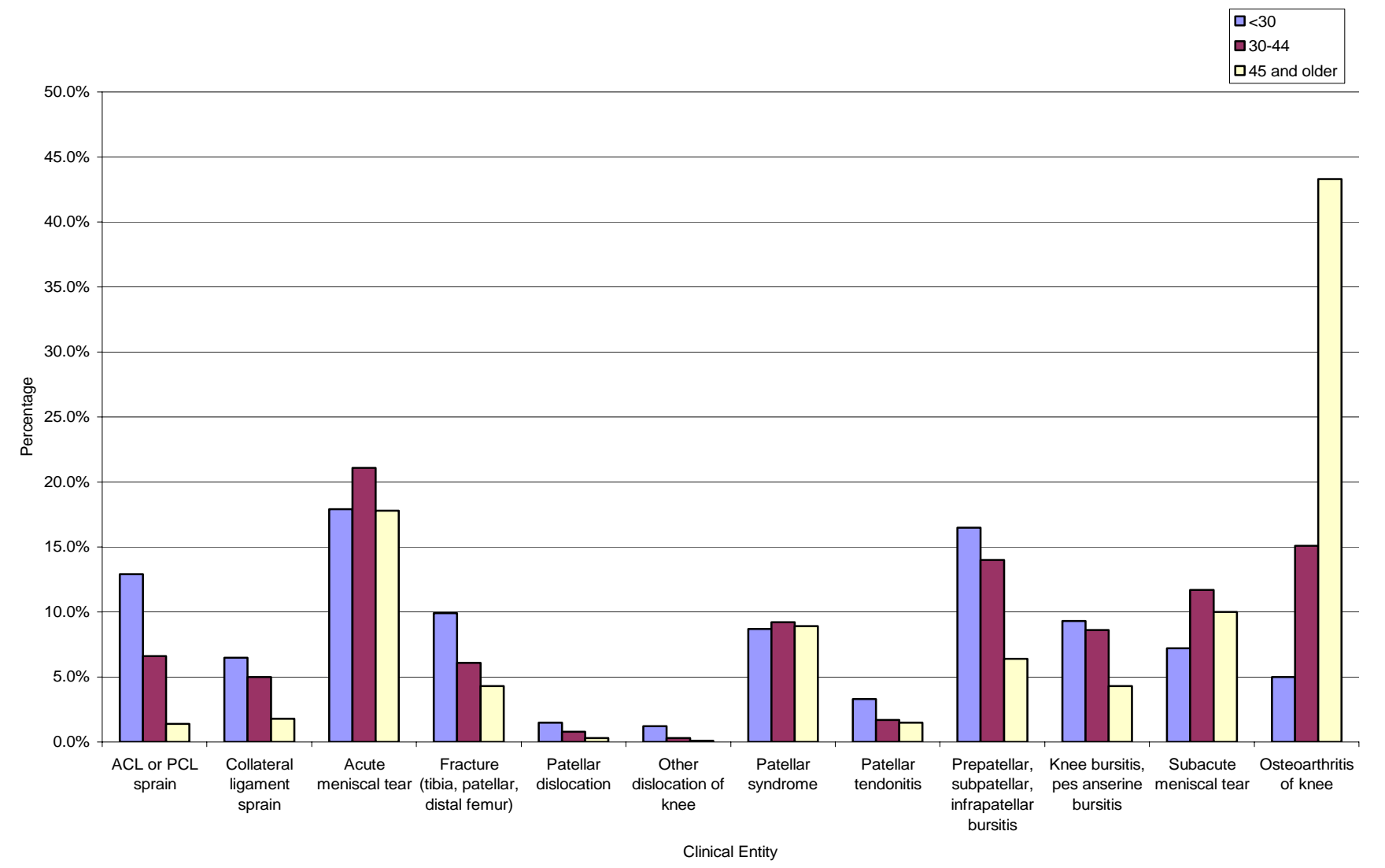

Fig. (3). Distribution of knee disorders stratified by age groups.

Table 3. Distribution of Specific Knee Disorders within Job Class (\% of Incident Cases)

\begin{tabular}{|c|c|c|c|}
\hline & Outside Journeymen & Floor Layer Journeymen & Outside Apprentices \\
\hline \hline Osteoarthritis & $\mathbf{3 2 . 6}$ & 15.3 & 8.6 \\
\hline Meniscal injuries & 29.0 & 26.9 & 31.2 \\
\hline Bursitis & 14.7 & $\mathbf{3 2 . 1}$ & 17.5 \\
\hline ACL/PCL sprain & 3.9 & 4.2 & $\mathbf{1 3 . 6}$ \\
\hline Fracture & 5.3 & 5.8 & $\mathbf{1 0 . 9}$ \\
\hline
\end{tabular}

covered by the Fund. Also, the transient nature of employment in construction in general seemed to have influence in producing injury under-report since most workers move to a new employer after finishing the present job. In addition, workers may fear that if they file a claim as work-related, they may be passed over for future jobs. All these patterns could easily lead to the elevation of number of claims in this Fund. As a result, the inclusion of both work-related and non-work-related cases might have unduly resulted in higher rates than those reported in the literature which were usually restricted to work-related cases only.

On the other hand, since we do not have the number of work hours for the carpenters who did not file claims (considered as non-cases), we were not able to report more accurate incident rates. However, should that number be available, it might result in an increase in total hours of work which is the denominator to calculate the incident rates. Consequently, we might expect to see lower incident rates.

The knee disorder distribution patterns in this study tended to indicate that the longer a worker is employed in the trade, the more chronic the disease category. The result that Floor Layer Journeymen had a much higher percentage of bursitis is consistent with prior studies, although the comparative groups are different $[6,14]$.

In the present study, Outside Journeymen had a much higher percentage of OA than Floor Layer Journeymen and Outside Apprentices. As OA generally develops over many years, it was usually concluded that this specific chronic disorder has a multifactorial etiology. There are several major risk factors that have been associated with OA including advancing age, obesity, family history, a history of a significant knee joint injury, and a history of exposure to physically 
demanding work [31]. Although work exposure was not examined in the current stage of the study, we surmise that Outside Journeymen may be at higher risk for subsequent $\mathrm{OA}$ on the basis of cumulative exposure to heavy lifting, squatting and twisting as well as a history of meniscal and ligament injury and other internal derangements. On the other hand, age might be a potentially strong confounder, as $63.4 \%$ of Outside Journeymen are 45 years old/older in comparison to $32.8 \%$ for Floor Journeymen and $5.8 \%$ for Outside Apprentices. Overall, the study found that older workers were diagnosed with OAs more frequently, which might have suggested that age is a powerful personal factor for OA [32].

The relationship between gender and knee $\mathrm{OA}$ is rather complicated. Population studies in developed and developing countries reported by WHO [33] have consistently reported a higher prevalence of radiographic knee osteoarthritis (knee ROA) in women than in men from middle age onwards. Similarly, women tend to report knee pain more frequently than men $[34,35]$. One might surmise a corresponding excess of symptomatic knee OA (the combination of knee pain and ROA) among women. However, several studies have found contradictory results. It seems that there are different patterns among different age groups between women and men [36-38]. In the present study, females were diagnosed with OA slightly more often than males, but this could be greatly shaped by the fact that the study population is predominantly male.

The examination of the distribution of specific disorders among different job classes permitted the comparison of the relative proportion of acute knee disorders to subacute and chronic conditions. It should be recognized though, that the number of acute cases might have been underestimated because acute occupational knee injuries are likely to be managed as workers' compensation claims and not in the personal medical claims database. Nonetheless, the workers' compensation "filter" [39] is not perfect, so an examination of the distribution of acute conditions compared to those in the subacute and chronic groups in different job classes should provide useful information.

This classification system was based on a clinically reasonable algorithm with the investigators blind to any personal identifiers when coding incident cases. Although the results followed expected patterns by age, gender and job class, it was not within the plan of this study to verify results by a review of actual medical records or other gold standard of diagnostic coding claims. Since it is impossible to conduct a formal evaluation of sensitivity and specificity, relative agreement among different definitions must suffice to provide some understanding of the relative merits of each. Despite our inability to verify diagnostic categorization, we were able to cross reference the ICD-9 codes to the CPT procedures to demonstrate clinical feasibility of treatment with specific diagnoses, especially for those cases with more than one visit in the study interval.

The classification of knee disorders into three broad categories (acute, subacute, and chronic) allowed us to use clinically reasonable methods to simply examine the characteristics of knee disorders. The study results have provided fundamental health outcome information for further study of knee disorders and occupational risk factors. The continuing examination of the relationship between work-related exposures and different types of knee disorders is warranted.

In the future, we plan to work with the local Homebuilders' Association and with individual residential contractors to get access to workers' compensation records. This will allow us to estimate the burden of injury posed by knee disorders that are reimbursed with workers' compensation benefits rather than the Fund. At the same time, we will be able to classify their cases to match our case definitions in the present study, and then quantify the number of claims for medical care, temporary disability, and permanent disability.

\section{CONCLUSION}

Using the medical insurance records provided us with the opportunity to systematically evaluate knee disorders of varying levels of acuity and chronicity in a broad group of working carpenters. This method of categorization produced expected results by showing similar incidence rates compared to other studies, higher occurrence of OA among older workers, and more acute injuries among apprentices. This classification system may be used to address some fundamental questions about the risk factors of knee injuries and disorders. Beyond this effort, and with the assistance of the workers' compensation records, the relative risk of knee disorders among different groups of interest could be determined to facilitate the understanding of knee disorder causations.

\section{ACKNOWLEDGEMENTS}

The authors acknowledge The Carpenters' Health and Welfare Trust Fund of St. Louis for providing the necessary data for these analyses. This work was supported by a grant from the National Institute for Occupational Safety and Health (5R01-OH008254). The contents in this article are solely the responsibility of the authors and do not necessarily represent the official views of NIOSH.

\section{REFERENCES}

[1] Brenner H, Ahern W. Sickness absence and early retirement on health grounds in the construction industry in Ireland. Occup Environ Med 2000; 57: 615-20.

[2] Kirkeskov Jensen L, Mikkelsen S, Loft IP, Eenberg W. Workrelated knee disorders in floor layers and carpenters. J Occup Environ Med 2000; 42: 835-42.

[3] BLS. http://www.bls.gov/oco/ocos203.htm (accessed on March 15, 2010), 2010.

[4] Ekström H, Engholm G, Nyqvist B, Wallenquist A. Knee Complaints as an Occupational Problem. Bygghälsans Forskningsstiftelse, Stockholm 1983.

[5] Tanaka S, Smith AB, Halperin W, Jensen R. Carpet- layer's knee (letter to the editor). N Engl J Med 1982; 307: 1275-6.

[6] Tanaka S, Lee ST, Halperin WE, Thun MJ, Smith AB. Reducing knee morbidity among carpet layers. Am J Public Health 1989; 79: 334-5.

[7] Bhattacharya A, Mueller M, Putz-Anderson V. Traumatogenic factors affecting the knees of carpet installers. Appl Ergon 1985; 16: $243-50$.

[8] Village J, Morrison JB, Leyland A. Biomechanical comparison of carpet-stretching devices. Ergonomics 1993; 36: 899-909.

[9] Vingård E, Alfredsson L, Goldie I. Occupation and osteoarthrosis at the hip and knee: A register-based cohort study. Int J Epidemiol 1991; 20: 1025-31.

[10] Kivimäki J, Riihimäki H, Hänninen K. Knee disorders in carpet and floor layers and painters. Scand J Work Environ Health 1992; 18: 310-16. 
[11] Kirkeskov Jensen L, Mikkelsen S, Loft IP, Eenberg W, Bergmann I, Løgager V. Radiographic knee osteoarthritis in floorlayers and carpenters. Scand J Work Environ Health 2000b; 26: 257-62.

[12] Kirkeskov Jensen L. Knee-straining work activities, self-reported knee disorders and radiographically determined knee osteoarthritis. Scand J Work Environ Health 2005; 31(Suppl 2): 68-74.

[13] Seidler A, Bolm-Audorff U, Abolmaali N, Elsner G. The knee osteoarthritis study-group. The role of cumulative physical work load in symptomatic knee osteoarthritis - a case-control study in Germany. J Occup Med Toxicol 2008; 3: 14.

[14] Thun M, Tanaka S, Smith $\mathrm{AB}$, et al. Morbidity from repetitive knee trauma in carpet and floor layers. Br J Ind Med 1987; 44: 61120.

[15] Rytter S, Kirkeskov Jensen L, Bonde JP. Clinical knee findings in floor layers with focus on meniscal status. BMC Musculoskelet Disord 2008; 9: 144

[16] Arndt V, Rothenbacher D, Brenner H. Older workers in the construction industry: results of a routine health examination and a five year follow up. Occup Environ Med 1996; 53: 686-91.

[17] Dimov M, Bhattacharya A, Lemasters G, Atterbury M, Greathouse L, Ollila-Glenn N. Exertion and body discomfort perceived symptoms associated with carpentry tasks: an on-site evaluation. Am Ind Hyg Assoc J 2000; 61: 685-91.

[18] Lemasters GK, Atterbury MR, Booth-Jones AD, et al. Prevalence of work related musculoskeletal disorders in active union carpenters. Occup Environ Med 1998; 55: 421-7.

[19] Armstrong EP, Manuchehri F. Ambulatory care databases for managed care organizations. Am J Health Syst Pharm 1997; 54: 197383.

[20] Davidoff F. Databases in the next millennium. Ann Intern Med 1997; 127(8 Pt 2): 770-4.

[21] Lave JR, Pashos CL, Anderson FG, et al. Costing medical care: using Medicare administrative data. Med Care 1994; 32: 1577-89.

[22] Mitchell JB, Bubolz T, Paul JE, et al. Using Medicare claims for outcomes research. Med Care 1994; 32: 1538-51.

[23] Lipscomb HJ, Dement JM, Loomis DP, Silverstein B, Kalat J. Surveillance of work-related musculoskeletal injuries among union carpenters. Am J Ind Med 1997; 32: 629-40.

[24] Harrold LR, Yood RA, Andrade SE, et al. Evaluating the predictive value of osteoarthritis diagnoses in an administrative database. Arthritis Rheum 2000; 43: 1881-5.

[25] Katz JN, Barrett J, Liang MH, et al. Sensitivity and positive predictive value of Medicare Part B physician claims for rheumatologic diagnoses and procedures. Arthritis Rheum 1997; 40: 1594-600.

[26] Katz JN, Losina E, Barrett J, et al. Association between hospital and surgeon procedure volume and outcomes of total hip replacement in the United States Medicare population. J Bone Joint Surg Am 2001; 83-A: 1622-9.
[27] Punnett L. The costs of work-related musculoskeletal disorders in automotive manufacturing. New Solutions. J Environ Occup Health Policy 1999; 9: 403-26.

[28] Picavet HS, Hazes JM. Prevalence of self-reported musculoskeletal diseases is high. Ann Rheum Dis 2003; 62: 644-50.

[29] Spector TD, Hart DJ. How serious is knee osteoarthritis? Ann Rheum Dis 1992; 51: 1105-6.

[30] Yuan L, Buchholz B, Fulmer S, Jing X. Knee disorders among union carpenters: Proceedings of the $17^{\text {th }}$ World Congress on Ergonomics; 2009 Aug 9-14; Beijing, China. International Ergonomics Association 2009.

[31] Felson DT. The epidemiology of osteoarthritis: prevalence and risk factors. In: Osteoarthritic disorders (eds. Kuettner KE, Goldberg VM). Rosemont: America Academy of Orthopaedic Surgeons 1995; pp. 13-24.

[32] Cicuttini FM, Spector TD. Evidence for the increasing prevalence of osteoarthritis with aging; does this pertain to the oldest old? In: Osteoarthritis - public health implications for an aging population (ed. Hamerman D). Baltimore, MD: The Johns Hopkins University Press 1997; pp. 49-62.

[33] World Health Organization. The burden of musculoskeletal conditions at the start of the new millennium (WHO Technical Report Series No. 919). Geneva: WHO 2003.

[34] Andersen RE, Crespo CJ, Ling SM, Bathon JM, Bartlett SJ. Prevalence of significant knee pain among older Americans: results from the Third National Health and Nutrition Examination Survey. J Am Geriatr Soc 1999; 47: 1435-8.

[35] Thomas E, Peat G, Harris L, Wilkie R, Croft PR. The prevalence of pain and pain interference in a general population of older adults: cross-sectional findings from the North Staffordshire Osteoarthritis Project (NorStOP). Pain 2004; 110: 361-8.

[36] Dillon CF, Rasch EK, Gu Q, Hirsch R. Prevalence of knee osteoarthritis in the United States: arthritis data from the Third National Health and Nutrition Examination Survey 1991-94. J Rheumatol 2006; 33: 2271-9.

[37] Lacey RJ, Thomas E, Duncan RC, Peat G. Gender difference in symptomatic radiographic knee osteoarthritis in the Knee Clinical Assessment - CAS $(\mathrm{K})$ : A prospective study in the general population. BMC Musculoskelet Disord 2008; 9: 82.

[38] Peat G, Thomas E, Duncan R, et al. Estimating the probability of radiographic osteoarthritis in the older patient with knee pain. $\mathrm{Ar}-$ thritis Rheum 2007; 57: 794-802.

[39] Azaroff LS, Levenstein C, Wegman DH. Occupational injury and illness surveillance: conceptual filters explain underreporting. Am J Public Health 2002; 92: 1421-9.

Received: June 27, 2011

Revised: July 16, 2011

Accepted: July 18, 2011

(C) Yuan et al.; Licensee Bentham Open.

This is an open access article licensed under the terms of the Creative Commons Attribution Non-Commercial License (http://creativecommons.org/licenses/by-nc/3.0/) which permits unrestricted, non-commercial use, distribution and reproduction in any medium, provided the work is properly cited. 